\title{
Representação de Saúde da Família por alunos participantes em um projeto de extensão universitária
}

https://doi.org/10.11606/issn.1981-4690.v35i1p143-157
Diogo Gonçalves de Souza de Oliveira/*** Giannina do Espírito-Santo ${ }^{* * * * * * * *}$ Silvia Maria Agatti Lüdorf* Alexandre Palma ${ }^{* / * * * * *}$

\section{Resumo}

Este estudo se desenvolveu no viés da articulação entre ensino/serviço/pesquisa/comunidade, pois se origina a partir de um projeto de extensão universitária (PEU) no âmbito da Estratégia Saúde da Família (ESF), que teve como objetivo analisar as representações dos estudantes de Educação Física em atuação na ESF em um Centro Municipal de Saúde do Rio de Janeiro. Trata-se de uma pesquisa qualiquanti, em que a quantitativa foi abordada por meio do Núcleo Central das Representações Sociais (RS) pelas associações livres de ideias e na qualitativa fez-se uso do referencial teórico-metodológico das RS por meio da abordagem processual. Foi possivel evidenciar que os estudantes percebem sua participação de forma favorável neste setor, além de visualizarem modificações significativas em sua formação, a partir da intervenção multidisciplinar.

PalaVRAS-Chave: Educação Física; Exercício; Educação superior; Atenção básica à saúde; Sistema Único de Saúde.

\section{Introdução}

A universidade no século XXI necessita passar por transformaçóes, visto que a abordagem disciplinar ainda presente favorece o conhecimento verticalizado, fragmentado e muitas das vezes descontextualizado em relação ao âmbito social. A articulação entre as esferas ensino/extensão/ comunidade/pesquisa torna-se um instrumento favorável para uma formaçáo mais ampliada e de um estudante mais crítico ${ }^{1}$.

Neste sentido, a participação dos graduandos em projetos de extensão, por exemplo, no âmbito da Atenção Básica à Saúde (ABS) pode contribuir para a relação entre os seus conhecimentos adquiridos no decorrer da vida como cidadão, com os vistos em sala de aula e com os saberes do território/da comunidade $^{2}$, permitindo um olhar diferenciado para a atuaçáo nesse campo.

Como o estudo trata sobre representaçóes sociais (RS) na atuação na Estratégia Saúde da Família (ESF) e que traz uma grande possibilidade de vinculação com as RS de saúde, foi realizada

uma busca na base de dados Scielo Brasil, sem pretensões de sistematização. Foi possível verificar que há um predomínio de representaçóes de saúde no viés biomédico nos mais diferentes grupos. A busca recuperou 14 artigos que tratavam das RS de saúde, destes foram analisados oito ${ }^{3-10}$. Em todos eles os resultados apontaram para o viés biomédico dessas RS de saúdea. Esse cenário dá pistas de que a saúde é representada no senso comum dentro dessa perspectiva. Este fato pode refletir em dificuldades na inserçáo de profissionais na $\mathrm{ABS}$, visto que a maneira pela qual se entende o que é saúde vai favorecer a sua forma de atuação.

FonsÊCA et al. ${ }^{11}$ avaliaram o Programa Educação pelo Trabalho em Saúde (PET-Saúde) em Programas de Saúde da Família em São Paulo e detectaram que este programa auxilia na ampliação do olhar sobre o processo saúde/doença, no trabalho interdisciplinar, bem como no processo de formaçáo dos graduandos. Os autores acreditam que o PETSaúde pode colaborar significativamente para a
*Universidade Federal do Rio de Janeiro, Rio de Janeiro, RJ, Brasil. **Departamento de Educação Física, Uniabeu Centro Universitário, Belford Roxo, RJ, Brasil.

*** Universidade Gama Filho, Rio de Janeiro, RJ, Brasil.

****Comissão Nacional de Ética em Pesquisa com Seres Humanos - CONEP, Brasília, DF, Brasil.

*****Fundação

Oswaldo Cruz, Rio de Janeiro, RJ, Brasil. 
formação crítica dos graduandos, especialmente em Educação Física, pois proporciona o trabalho interprofissional ${ }^{b, 12}$ e o desenvolvimento de competências e habilidades associadas aos princípios do Sistema Único de Saúde (SUS).

Alguns dos profissionais que compóem a ESF são favoráveis à inserção do profissional de Educação Física na $\mathrm{ABS}$, porém a visão destes ainda está centrada na prescrição de exercícios e desenvolvimentos de atividades com as pessoas que possuem doenças crônicas não-transmissíveis, e também há um desconhecimento do Núcleo de Apoio à Saúde da Família $(\mathrm{NASF})^{13}$.

Em que pese a contribuição advinda da inserção de graduandos nos serviços de saúde, parece haver uma lacuna no que se refere à abordagem desses conteúdos na graduação. PASQUIM ${ }^{14}$ verificou

\section{Método}

Antes de abordar especificamente sobre o método, é interessante ressaltar que o pensamento de Domingos Sobrinho ${ }^{16}$, que discorre sobre a Teoria das Representaçóes Sociais, conquistou espaços no campo das Ciências Humanas e Sociais contemporâneas, visto que possibilitou desvelar questóes deixadas pela crise do paradigma dominante $e^{c, 17}$, contribuindo para estabelecer novas hipóteses para velhos problemas.

Este estudo se desenvolve no viés da articulação entre ensino/serviço/pesquisa/comunidade ${ }^{\mathrm{d}}$, pois se origina a partir de um projeto de extensão universitária (PEU) no âmbito da ESF, desenvolvido pelo curso de bacharelado em Educação Física de um Centro Universitário, na cidade do Rio de Janeiro. A proposta do PEU é trabalhar junto às equipes de ESF possibilitando a ampliação do cuidado e a vivência dessa realidade. Os estudantes têm a oportunidade de realizar o diagnóstico do território por meio das visitas domiciliárias ${ }^{\mathrm{e}, 18}$, participar das reuniôes de equipe e dos Conselhos Distritais de Saúde ${ }^{f}$, de consultas compartilhadas ${ }^{\mathrm{g}, 19}$, ou seja, de todos os processos de trabalho realizado pela Estratégia Saúde da Família, além da realização de práticas corporais para os usuários, junto com o orientador das atividades (professor responsável pelo PEU).

A Unidade de Saúde possui três equipes de saúde da família, com uma média de 4.000 pessoas, cada uma. Como esta Unidade é tipo $\mathrm{B}$, tendo atendimento por demanada para as que a Saúde Coletiva nos cursos de graduação em Educação Física de duas instituições de ensino público de São Paulo está marginalizada, com pouca carga horária e raras atuaçóes na $\mathrm{ABS}$. Já FALCI e BeLISÁrio ${ }^{15}$ identificaram que a procura por curso Lato Sensu em Saúde da Família se devia principalmente à busca de informaçóes não contempladas na graduação, referentes à incipiência desta no que tange à preparação para atuarem na ABS.

A partir deste cenário ainda em transformação para novos caminhos a serem trilhados para a graduação em Educação Física, o presente estudo tem como objetivo analisar as representaçóes sociais dos estudantes de Educação Física em atuação na Estratégia Saúde da Família em um Centro Municipal de Saúde do Rio de Janeiro.

especialidades e a ESF, além de cerca dos 12.000 adscritos, ainda recebe um número elevado de pessoas de outras regióes são referenciadas por outros serviços para o atendimento de suas necessidades.

Os critérios de inclusão para participar da pesquisa foram: i) ser estudante do curso de bacharelado em Educação Física; ii) estar matriculado ou ter cursado a disciplina Atividade Física e Promoção da Saúde; iii) estar engajado no projeto de extensão; e iv) ser maior de 18 anos de idade. Cabe ressaltar, que os estudantes permaneciam por um semestre no projeto e na disciplina, sendo assim todos tinham o mesmo tempo de vivências no campo e na disciplina.

A pesquisa foi realizada entre os anos de $2012 \mathrm{e}$ 2014, sendo que, ao final de cada período letivo (a cada seis meses), todos os estudantes que participaram do projeto eram levados, separadamente a uma sala disponibilizada na unidade de saúde para realização da entrevista junto com o professor responsável pelo PEU. Utilizou-se a entrevista semiestruturada, em que se discorreu sobre determinado tema com o objetivo de obter informaçóes construídas por meio da vivência no campo ${ }^{20}$.

As questóes presentes na entrevista estavam relacionadas aos significados de Exercício Físico, Saúde Pública e de Cuidado, o motivo para participação no projeto, o dia a dia de participação no projeto, se a participação ocasionou alguma mudança em sua percepção no trabalho em equipes multidisciplinares e a aplicação dos conhecimentos 
adquiridos na vivência do projeto.

Participaram da pesquisa 32 estudantes, 13 do sexo masculino e 19 do feminino. A média de idade foi de 30,4 anos (com desvio padrão de 8,5 anos), sendo a faixa etária predominante entre 25 e 34 anos $(n=14)$. Além disso, preponderantemente, os informantes cursavam a graduação em Educação Física entre o sétimo e oitavo períodos $(\mathrm{n}=28)$.

Trata-se de uma pesquisa qualiquanti, em que a quantitativa foi abordada pelo Núcleo Central das Representaçôes Sociais pelas associações livres de ideias. Esta técnica permite, por meio de termos indutores (Exercício Físico, Saúde Pública e Cuidado), que seja possível chegar a determinados elementos para compor a Representação Social deste grupo de estudantes. Para alcançar o núcleo central, usou-se como base a ordem média de evocação e a frequência das três palavras mencionadas pelos participantes para cada termo indutor ${ }^{21}$.
Para encontrar a Ordem Média de Evocação (OME), é necessário realizar um cálculo que é a média ponderada das frequências divididas pelo somatório das mesmas. A distribuição das palavras no quadro é determinada, graficamente, por todas as médias das frequências (representada no eixo Y) e da OME (representada pelo eixo X). A partir desses cruzamentos, os que estiverem situados no quadrante inferior direito são classificadas como segunda periferia, que são termos ditos mais tardiamente com baixa frequência; a primeira periferia e zona de contraste (quadrante superior direito e inferior esquerdo) são elementos que podem ser ditos com baixa frequência e serem evocados mais rapidamente ou alta frequência com evocação mais tardia e, por fim, o núcleo central, localizado no quadrante superior esquerdo, que indica a centralidade da representação estudada, além de ser o elemento mais estável das representações ${ }^{21,22}$, como pode ser visto no QUADRO 1.

QUADRO 1 - Quadro das quatro casas.

\begin{tabular}{|c|c|}
\hline $\begin{array}{c}\text { Núcleo Central } \\
(\mathrm{F}=\text { alta; OME= baixa })\end{array}$ & $\begin{array}{c}1^{\circ} \text { Periferia } \\
(\mathrm{F}=\text { alta; } \text { OME }=\text { alta })\end{array}$ \\
\hline $\begin{array}{c}\text { Zona de Contraste } \\
(\mathrm{F}=\text { baixa; OME= baixa })\end{array}$ & $2^{\circ}$ Periferia \\
\end{tabular}

Legenda: Frequência (F); Ordem Média de Evocação (OME).

Fonte: Os autores
$\mathrm{Na}$ abordagem qualitativa utilizou-se o referencial teórico-metodológico das Representaçôes Sociais com o propósito de compreender as representaçóes dos estudantes de Educação Física sobre as vivências no campo da Estratégia Saúde da Família. Segundo JODELET $^{23}$, estas representaçóes simbolizam o pensamento social por meio de suas manifestaçóes em seu cotidiano, em que o senso comum é parte essencial desse processo.

Foram utilizados os estágios de interpretação das Representaçóes Sociais pela abordagem processual abordadas por ARRUDA ${ }^{24}$. Segundo a autora, para atingir a representação social, que indica um pensamento integrado pelas relaçóes identificadas (estágio final), é necessário que passe primeiramente pelo estágio de categorização ( $1^{\circ}$ estágio), em que se arremata com referência em relação aos objetivos da pesquisa (2o estágio). No terceiro estágio, será estabelecido um aspecto cabal por meio de interseçóes ou ocorrências para realização de articulaçóes em busca da manutenção destas, para que não sejam mera lista de categorias e repetiçóes isoladas.

A análise dos dados foi realizada por meio da análise do conteúdo na vertente temática proposta por BARDIN ${ }^{25}$, pois esta técnica tem por objetivo ir além do aparente e do dito. Ela busca captar e interpretar desocultando as informaçóes necessárias para, a partir das recorrências de falas, atribuir as representaçóes do grupo estudado, fato que proporciona a consonância com as etapas propostas por ARRUDA ${ }^{24}$.

O presente estudo foi aprovado pelo Comitê de Ética e Pesquisa do Centro Universitário Augusto Motta (UNISUAM) sob o Certificado de Apresentação para Apreciação Ética no 19928413.8.0000.5235 e parecer no 447.392. $\mathrm{O}$ estudo atendeu ainda à Resolução 466/12 
do Conselho Nacional de Saúde sobre pesquisa com seres humanos, em que se manteve o respeito à privacidade, à imagem e à confidência das informaçóes fornecidas pelos

\section{Resultados e discussão}

A combinação desses métodos escolhidos visa ter uma maior compreensão e aproximação do contexto estudado para que se tenha uma visão ampliada sobre o fenômeno.

\section{Significados de Exercício Físico}

Como pode ser observado no QUADRO 2, o núcleo central para os significados de exercício físico está associado à Saúde $(\mathrm{F}=25 ; \mathrm{OME}=1,36)$ e Qualidade de Vida ( $\mathrm{F}=14 ; \mathrm{OME}=1,86)$. Isso sinaliza que estes alunos estấo caminhando para uma visão restrita da relação entre exercício físico e saúde, pois as enunciaçóes localizadas na primeira periferia e zona de contraste apoiam essa visão.

Este tipo de olhar que estabelece uma relação de causa e efeito da prática corporal/atividade física e saúde, pautada na abordagem biomédicaepidemiológica, em que há contabilização de gastos calóricos, atribui o risco ao sedentarismo e a atividade física, como terapia não medicamentosa, acaba por predominar entre as publicaçóes que se relacionam à saúde pública ${ }^{27,28}$. Por outro lado, existe resistência a essa abordagem, que contrapóe essas normatizações e questôes prescritivas, pois são evidenciadas incongruências do que é o sedentarismo ${ }^{29}$ e, ainda reforçados por Ferreira, Castiel e Cardoso ${ }^{30}$ quando analisam a associação dos discursos da promoção da saúde, exemplificado através do programa Agita São Paulo, possuem uma abordagem comportamentalista, "que demoniza o sedentarismo, culpabiliza seus adeptos e apoia suas estratégias em mudanças comportamentais individuais como meio de redução do risco epidemiológico, independentemente dos condicionantes sociais, econômicos e culturais" (p. 865).

Nogueira e Bosi ${ }^{31}$ debatem sobre essas resistências no cenário da Educação Física, quando destacam:

[...] as iniciativas, as discussóes e as intervençôes que germinam na EFSC estão sendo profundamente reconfiguradas mediante a reconstruçấo de conceitos através do referencial crítico adotado no pensamento social sujeitos participantes da pesquisa, bem como a não utilização de maneira indevida dessas informaçóes em detrimento de qualquer aspecto do participante da pesquisa ${ }^{26}$. em saúde, um movimento crescente com o maior trânsito de profissionais de EF no campo da SC, operando uma busca permanente de superaçáo dialética nos saberes e nas práticas da EFSC (p. 1919) $)^{31}$.

Destaca-se aqui que a qualidade de vida, um dos significados atribuídos pelos estudantes, é um termo multifatorial que abrange sentimentos e significados subjetivos, reportados por meio de valores individuais e coletivos, setoriais e intersetoriais de diferentes períodos históricos e apresenta relação significativa com as necessidades econômicas e sociais ${ }^{32}$.

Por outro lado, SILva e LüDORF ${ }^{33}$ apontam que, mesmo dentre profissionais de Educação Física, pode preponderar uma compreensão mais simplista da relação entre a prática corporal/atividade física e saúde, na medida em que os professores investigados consideravam que alimentação balanceada e a prática corporal/atividade física poderia retardar o envelhecimento. Os autores complementam ainda que poucos tiveram uma visão ampliada sobre esses cuidados reportados, apenas ao lazer, descanso, relaçóes sociais, estudos e entretenimento.

\section{Significados de Saúde Pública}

As representaçôes sociais de Saúde Pública dos participantes desse estudo ficaram atreladas à Precariedade $(\mathrm{F}=28 ; \mathrm{OME}=1,75)$, Qualidade de Vida $(\mathrm{F}=9 ; \mathrm{OME}=2,00)$ e Obrigatoriedade $(\mathrm{F}=$ 5; OME= 1,60) (QUADRO 3). Isso pode estar relacionado às suas experiências pessoais e familiares no decorrer de suas vidas e à influência da avaliação da mídia, uma vez que surgem palavras na zona de contraste como Planejamento, Saneamento e Melhora; outro fator contribuinte pode ser o pouco contato e vivência com o complexo do Sistema Único de Saúde e seus desdobramentos durante sua graduação. Foram apresentadas também, enunciaçóes na zona de contraste e segunda periferia, como doença, melhora, necessário, que demonstram uma relaçáo com a perspectiva mais restrita para a saúde pública. 
QUADRO 2 - Significados de Exercício Físico.

\begin{tabular}{|c|c|}
\hline $\begin{array}{c}\text { NÚCLEO CENTRAL } \\
\text { Saúde }(\mathrm{F}=25 ; \text { OME }=1,36) \\
\text { Qualidade de Vida }(\mathrm{F}=14 ; \mathrm{OME}=1,86)\end{array}$ & $\begin{array}{c}1^{\circ} \text { PERIFERIA } \\
\text { Bem-estar }(\mathrm{F}=17 ; \text { OME }=2,29)\end{array}$ \\
\hline $\begin{array}{l}\text { ZONA DE CONTRASTE } \\
\text { Autoestima }(\mathrm{F}=2 ; \mathrm{OME}=2,00) \\
\text { Movimento }(\mathrm{F}=8 ; \mathrm{OME}=1,75)\end{array}$ & $\begin{array}{c}2^{\circ} \text { PERIFERIA } \\
\text { Condicionamento Físico }(\mathrm{F}=7 ; \mathrm{OME}=2,43) \\
\text { Alegria }(\mathrm{F}=2 ; \mathrm{OME}=2,50) \\
\text { Tempo }(\mathrm{F}=2 ; \mathrm{OME}=2,50) \\
\text { Socialização }(\mathrm{F}=2 ; \mathrm{OME}=2,50) \\
\text { Lazer }(\mathrm{F}=2 ; \mathrm{OME}=2,50)\end{array}$ \\
\hline
\end{tabular}

Médias para ponto de corte: F: 8,10 e OME: 2,17.

Legenda:

Frequência (F):

Ordem Média de Evocação (OME).

Fonte: Os autores

\section{QUADRO 3 - Significados de Saúde Pública.}

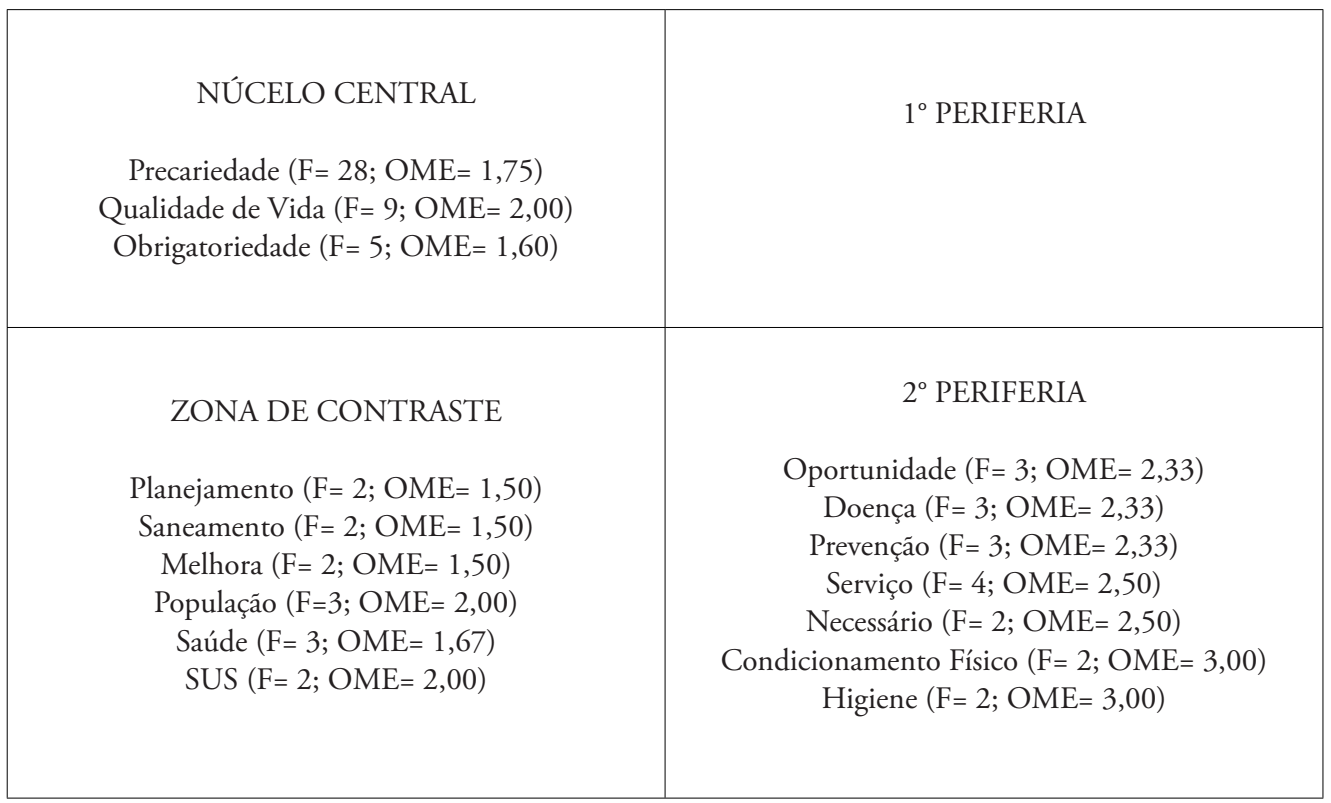

As dificuldades encontradas na formação não são exclusividade da Educação Física, Lopes e Bueno ${ }^{7}$ no artigo "Saúde Pública é...: permanências e modernidades nas representaçôes dos universitários" apontam que os estudantes de graduação em enfermagem, de oito diferentes turmas, veem com significados negativos a Saúde Pública (SP) e esta serve para quem não tem escolha, para pobres e excluídos. Esse quadro torna-se bastante preocupante, na medida em que muitos destes estudantes irão trabalhar na SP e, não apresentam um potencial transformador para esse fenômeno. Pode-se inferir que a formação desses estudantes precisa buscar elementos que venham a favorecer novos olhares mais ampliados sobre o tema.

As fragilidades na formação do profissional de
Médias para ponto de corte: F: 4,6 e OME: 2,09 . Legenda: Frequência (F); Ordem Média de Evocação (OME)

Fonte: Os autores 
Educação Física são corroboradas por RoDRIGUES et al. ${ }^{34}$ ao realizarem uma revisão sistemática em artigos originais entre os anos de 2005 e 2011. Os autores evidenciaram que a formação desta categoria está pouco direcionada ao trabalho interdisciplinar e centrada no desenvolvimento de atividades com grandes grupos. GUARDA et al. ${ }^{35}$ relatam que a formação deste profissional está focada nas ações prescritivas, nas doenças e nos procedimentos rendendo-se às demandas mercadológicas. Estes achados respaldam os resultados encontrados no presente estudo.

Este cenário retrata a incipiência de debates no âmbito da Saúde Coletiva na formação em Educação Física no qual pesa o fato que a graduação deve proporcionar uma formação generalista, mas esta precisa contemplar os elementos básicos para que o estudante tenha condiçóes de buscar autonomamente os conhecimentos necessários para a formaçáo do seu pensamento crítico.

BILIBIO $^{36}$, ao escrever um ensaio sobre a atuação na atenção básica de um profissional de Educação Física aponta para as armadilhas, que mesmo uma pessoa que se pretenda crítica pode cair nelas no seu dia a dia, visto que, mesmo que Ulisses (personagem designado pelo autor) quisesse fugir da lógica "atividade física produz saúde", ele acaba por reproduzir este quadro. Sendo assim, Bilibio ${ }^{36}$ discorre que "o mundo das práticas corporais em saúde é permanentemente invadido por forças estranhas, signos mundanos que forçam o pensar em ato" (p. 134) e por tal fato, é preciso uma formação crítica que permita ir além da prescrição e que esteja integrada às manifestaçóes culturais, potencializando as questóes lúdicas e artísticas relacionadas ao "mundano, com a vida e com o outro"(p. 135).

\section{Significados de Cuidado}

No QUADRO 4, são apresentados os significados de cuidados e as suas representações (núcleo central) percebidas pelos estudantes, que foram: Atenção $(\mathrm{F}=15 ; \mathrm{OME}=1,60)$, Prevenção $(\mathrm{F}=6 ; \mathrm{OME}=1,17)$ e Carinho $(\mathrm{F}=9$; $\mathrm{OME}=1,78)$. Este núcleo central pode estar associado às açóes permanentes, desenvolvidas no PEU principalmente pelo grupo das práticas corporais. O convívio dos alunos com os usuários proporciona um momento importante para saúde que é o da escuta, pois através desta é possível caminhar para além da execução dos procedimentos técnicos e acadêmicos e se aproximar da realidade local e das reais necessidades dos usuários. É possível dizer que os estudantes estáo tendendo à proposta de cuidado humanizado, pois atenção e carinho encontram-se na sua centralidade, entretanto também está localizado no Núcleo Central, como exposto acima, a prevençáo e quando olhamos para a zona de contraste, nos deparamos com termos como Alimentação, Saúde e Atendimento, que se alinham com um perfil mais biomédico. Rodrigues, Lima e RonCALli ${ }^{37}$ encontraram resultados que se aproximam dos achados deste estudo. Os autores apontam que o núcleo central apresentou elementos como atenção, amor e acolhimento, mas que os profissionais que atuam no Programa Saúde da Família investigados, ainda carregam valores tradicionais e conotaçóes banalizadas, que acabam por dificultar as formas mais efetivas de intervenção.

SAntos et al. ${ }^{38}$ evidenciaram que através do trabalho desenvolvido pela Enfermagem, em que os usuários das unidades de Saúde da Família do estado da Bahia demonstraram satisfação com escuta, acolhimento e resolutividade na prática do cuidado nas consultas, visitas domiciliárias e atividades educativas não somente nas unidades, mas também no território.

Este tipo de estratégia de aproximação entre unidade de saúde e populaçáo é favorável ao contexto, mormente quando realizada de forma conjunta (por exemplo, usuários e trabalhadores da saúde), pois possibilita a compreensão e atendimento às singularidades do grupo. Neste sentido, a observaçáo e a escuta tornam-se ferramentas fundamentais para o trabalho em saúde, principalmente para a Educação Física, pois contribuirá para a sensibilidade do profissional junto ao usuário ${ }^{39}$.

Gutierrez e Minayo ${ }^{40}$ desenvolveram uma revisão sobre cuidado e encontraram poucos artigos no período de 1995 a 2007, os artigos dentro do escopo da pesquisa foram predominantemente qualitativos e que exploravam os sentidos e significados do cuidado. Verificaram que embora os estudos trouxessem conceitos abrangentes sobre o cuidado (considerando questóes materiais, afetivas e sociais), não realizavam uma discussão em termos concretos. As autoras apresentam algumas possibilidades de conceituação do cuidado advindas da revisão realizada. Destacam que "há uma valorização do tempo e do carinho nas interações entre os sujeitos" (p. 1501). Citam Silva e Tonete quando afirmam que o "cuidado envolve compreensão de aspectos relacionais e 
afetivos, seja no serviço, seja na família” (p.1501). Consideram relevante que estejam incluídas no cuidado questóes culturais, as diferenças de classe, redes de apoio e integração da perspectiva de gênero.

No artigo "Profissionais como produtores de redes: tramas e conexôes no cuidado em saúde", por MaXiminio et al. ${ }^{41}$, os autores consideram que as redes podem ser decisivas, tanto no que diz respeito ao sistema de saúde, como aquelas estabelecidas através das relações. O fato dos estudantes participarem de alguma maneira dessas redes, favorece para que possam evidenciar as necessidades e os apoios recebidos pelos usuários através tanto do serviço quanto da comunidade. Essa vivência pode ter propiciado, para alguns, uma reestruturação de sua visão do cuidado.

QUADRO 4 - Significados de Cuidado.

\begin{tabular}{|c|c|}
\hline $\begin{array}{l}\text { NÚCLEO CENTRAL } \\
\text { Atenção }(\mathrm{F}=15 ; \mathrm{OME}=1,60) \\
\text { Prevençáo }(\mathrm{F}=6 ; \mathrm{OME}=1,17) \\
\text { Carinho }(\mathrm{F}=9 ; \mathrm{OME}=1,78)\end{array}$ & $\begin{array}{c}1^{\circ} \text { PERIFERIA } \\
\text { Cuidado }(\mathrm{F}=5 ; \mathrm{OME}=3,00)\end{array}$ \\
\hline $\begin{array}{l}\text { ZONA DE CONTRASTE } \\
\text { Alimentação }(\mathrm{F}=4 ; \mathrm{OME}=1,75) \\
\text { Saúde }(\mathrm{F}=3 ; \mathrm{OME}=1,67) \\
\text { Atendimento }(\mathrm{F}=2 ; \mathrm{OME}=1,00) \\
\text { Observar }(\mathrm{F}=2 ; \mathrm{OME}=1,50) \\
\text { Idoso }(\mathrm{F}=2 ; \mathrm{OME}=1,00)\end{array}$ & $\begin{array}{c}2^{\circ} \text { PERIFERIA } \\
\text { Necessidade }(\mathrm{F}=2 ; \mathrm{OME}=2,00) \\
\text { Respeito }(\mathrm{F}=3 ; \mathrm{OME}=3,00) \\
\text { Qualidade de Vida }(\mathrm{F}=3 ; \mathrm{OME}=3,00)\end{array}$ \\
\hline
\end{tabular}

Médias para ponto de corte: F:4,67 e OME:1,87. Legenda: Frequência (F); Ordem Média de Evocação (OME).

Fonte: Os autores.

\section{Motivação para participar do projeto}

O protagonismo estudantil em projetos de extensão é fundamental, pois ele se torna um instrumento importante para a formação deste aluno. Estas iniciativas, para algumas categorias da área da saúde, ainda são escassas ${ }^{11,42}$.

Os alunos participantes deste estudo precisam cumprir uma determinada carga horária de estágio supervisionado em alguns dos PEU em diversos âmbitos na área do curso de bacharelado em Educação Física disponibilizados pela instituição de ensino superior. Com isso, percebe-se que há, em alguns relatos dos estudantes, uma participação sem muito interesse na proposta oferecida pelo projeto por ser ainda uma área recente de atuação da Educação Física ou diferente das expectativas deles.

Necessidade de cumprir a carga horário de estágio (Estudante 21, feminino, 22 anos)

Fato de ter enquadrado nos meus horários, a princípio.
(Estudante 31, masculino, 32 anos).

Todavia, para outros, o projeto apresenta-se como uma oportunidade para ampliação de seus conhecimentos, uma nova área de atuação:

\footnotetext{
Conhecer mais sobre a área da saúde e a intervenção do profissional de Educação Física nesta área. (Estudante 10, feminino, 24 anos)
}

Porque eu acho que a Educação Física precisa estar mais voltada para área da saúde, ela fica muito no fitness e pouco voltada para área geral da saúde. (Estudante 18, feminino, 21 anos)

Embora sejam variados os motivos da participação dos estudantes no projeto, nota-se que há um esforço de alguns para conhecer melhor a proposta de intervenção em saúde, campo de atuação este ainda recente para o profissional de Educação Física, indo além do que já está bastante explorado na área.

Experiência semelhante relacionada à iniciação 
e participação em projeto de extensão foi relatada por LeIte et al. ${ }^{43}$, ao ingressarem no projeto extensionista desenvolvido pela Universidade Federal da Paraíba. No artigo, os autores apresentaram que as dificuldades estavam atreladas às complexidades advindas do próprio território de atuação, pois nem mesmo seus educadores mais experientes e com conhecimentos teóricos conseguiam solucioná-las. Entretanto, relatam que essas e outras dificuldades, principalmente relacionadas ao processo saúdedoença, conseguiram ser superadas por meio da construção do vínculo, no ambiente profissional do serviço e nas visitas domiciliares.

Silva, Ribeiro e Silva Jr. ${ }^{44}$ produziram um artigo a partir da experiência de estudantes da área da saúde em um projeto de extensão. Concluíram que a extensão na formação em saúde pode favorecer ao cuidado integral. Entretanto é preciso que "haja articulação acadêmica e se concilie assistência à indissociabilidade ensino-pesquisa-extensão; extensão é espaço de vivências e confrontos entre teoria e prática numa dinâmica dialógica, multiprofissional e socialmente compromissada"(p. 371).

Este tipo de relação entre ensino/serviço/ comunidade favorece o compartilhamento de conhecimentos, pois como mencionado anteriormente, os novos espaços fora da instituição de ensino proporcionam saberes e ambientes favoráveis para debate, possibilitando a compreensão de que os saberes são construídos coletivamente e náo apenas na academia ${ }^{1}$.

\section{Cotidiano no projeto}

O dia a dia na participação do PEU apresenta-se de forma positiva para os estudantes de Educação Física, visto que tiveram a oportunidade de conhecer um âmbito novo de atuação, bem como de aquisição e ampliação de seus conhecimentos, como se pode observar nas falas abaixo:

Foi de adquirir conhecimento mesmo. Não sabia como era, cursava a disciplina que na teoria é bem diferente. A prática é que nós podemos ter o esclarecimento de saber como realmente era esse tipo de projeto e como funcionava. (Estudante 28, masculino, 37 anos)

Por ser novidade fez com que eu buscasse, estudasse mais sobre o assunto, foi mais motivante e até pelo professor que proporcionou, foi o elo (né) do conhecimento e facilitou bastante à aprendizagem no estágio dá até para pôr em prática aquilo que aprendi na teoria e na sala de aula. (Estudante 32, masculino, 36 anos).

Esses relatos remetem a uma concepção de educação para além da bancária, conforme denunciava Freire ${ }^{45}$, que se limitaria à ação dos professores depositarem informaçóes em seus recipientes (os estudantes). A participação no projeto em ambiente novo a ser desvelado pelos discentes favorece o seu protagonismo, possibilitando que se tornem atores fundamentais na construção de conhecimentos em saúde e intervenção ${ }^{2}$. Desta forma, alia-se à proposta de Freire ${ }^{45}$ de uma educação emancipadora.

Os presentes achados são corroborados por CAldas et al. ${ }^{46}$ quanto à participação dos estudantes no PET-Saúde de Minas Gerais, em que mais da metade dos alunos indicou que a aprendizagem no campo de atuação, o crescimento profissional e o trabalho interdisciplinar são alguns dos motivos para continuarem a participar deste programa. Uma possível justificativa para tal fato pode estar relacionada à oportunidade dos estudantes exercerem e terem a vivência de suas profissóes na ABS, o que contribuiu para a melhor compreensão das facilidades e das dificuldades advindas do território e do próprio serviço.

A aproximação dos conhecimentos entre a população e o meio acadêmico já vem sendo discutida há algum tempo e encontra reforço nas falas expostas anteriormente. SANTOS ${ }^{47}$ apresenta o conhecimento pluriversitário, que se trata de um pensamento com maior aproximação à realidade e aplicação de fato ao contexto inserido, como proposta de superação do modelo disciplinar e fragmentado de pensamento que, de certa maneira, ainda está presente na academia.

FonsÊCA et al. ${ }^{11}$ relatam que esta aproximação favorece a aprendizagem sobre o SUS, na medida em que o contato com a comunidade auxilia na formação dos alunos e estes se sentem profissionais diferenciados em relação aos outros que não participaram do projeto. Esses resultados são semelhantes aos relatos encontrados no presente estudo:

O dia a dia foi muito proveitoso. Aprendi muito sobre SUS, sobre o funcionamento da clínica da família, tirei muitas dúvidas. Participei e pude observar várias campanhas e várias açôes. (Estudante 25, feminino, 21 anos)

Cada dia foi uma novidade. [...] Numa quadra conheci crianças que tinham doenças, conheci a fábrica de plástico, a saúde da família, fomos à comunidade, fizemos a festa do dia 
das crianças... E, para mim, sempre que eu saía de casa era uma novidade, porque [...] sempre teria algo de diferente. (Estudante 6, masculino, 30 anos).

Pode-se perceber que os dados levam à possibilidade de uma formação menos fragmentada, favorecendo a um olhar ampliado sobre os fenômenos e com perspectivas de atuação alinhadas aos princípios e diretrizes do SUS.

\section{Percepçáo de mudança}

Os estudantes, quando questionados em relação à percepção de mudança sobre a atuação na $\mathrm{ABS}$, após a participação no projeto apresentam uma percepção negativa. Esta pode estar atrelada aos significados de Saúde Pública, reportado anteriormente por meio da técnica de associação livre de ideias, em que a enunciação com maior frequência foi a precariedade como seu núcleo central. Vale destacar que esta enunciação é a representação mais estável para este grupo.

Não mudou. Para mim continua da mesma forma. É um público que precisa de muita atenção. (Estudante 23, feminino, 23 anos)

Cara, posso dizer a verdade? Náo mudou náo, tudo que eu pensava eu vi e encontrei lá. (Estudante 11, feminino, 27 anos)

Uma possível justificativa para tal percepção pode estar associada às experiências trazidas e vividas por eles ou mesmo seus pais e/ou familiares em relação à Saúde Pública, especificamente no caso do Rio de Janeiro. Segundo a Secretaria Municipal de Saúde e Defesa Civil do Rio de Janeiro, as unidades de Saúde da Família, no ano de 2008, atendiam apenas 3,5\% da população da cidade e passaram a atender $41 \%$ em 2013, tornando um serviço muito recente para a

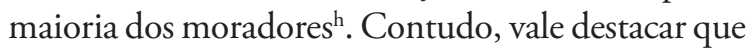
com este cenário na atenção primária em expansão no Rio de Janeiro, aumentam as possibilidades de modificação desta percepção, como pode ser visto:

Mudou na maneira que a gente vê a saúde, eu não imaginava que existia um professor de educação física dentro da saúde pública em um projeto de promoçáo da saúde e mudou na forma de ver a saúde pública com um professor de educação física fazendo a promoção. (Estudante 5, feminino, 28 anos)
É mudou sim, claro. Eu percebi que o trabalho na atenção básica ele atende muito a área social, a comunidade e é um projeto que tem que ser levado para todas as áreas, por exemplo, eu moro em Duque de Caxias, lá não tem um projeto igual a esse. Eu queria muito que tivesse, mas não tem e se torna uma coisa assim bem participativa, comunidade, posto de saúde e educadores físicos. Cada um agindo cooperativamente. Poxa eu achei muito legal esse trabalho, que até então eu não sabia que existia. (Estudante 26, masculino, 28 anos).

SAntos e BenedetTi ${ }^{48}$ verificaram que a inserção do profissional de Educação Física na atenção primária por meio do Núcleo de Apoio à Saúde da Família ainda é incipiente, uma vez que a sua distribuição privilegia apenas algumas regiốes do Brasil. Acrescentam, ainda, que a relação entre o atendimento profissional e a população assistida é extremamente desproporcional (sendo 1 para 100 mil pessoas). Cabe ressaltar que se entende as práticas corporais como sendo uma manifestação cultural e, por isso, acontece com maior potência em espaços não controlados, ou seja, com menor prescrição $0^{36}$. Para tanto, é preciso ter espaços favoráveis e com segurança para sua realização, o frequente quadro de violência presente nos grandes centros acaba por desfavorecer essas expressóes da cultura das práticas corporais.

Os participantes deste estudo avaliaram o contato com o serviço de forma positiva, o que contribuiu para novos olhares para as possibilidades de atuação:

Com certeza sim, o ponto mais relevante foi trabalhar... no caso, estagiar, né? Conhecendo o dia a dia e a vivência de cada profissional que trabalha na casa de saúde. (Estudante 16, masculino, 33 anos).

Sim. Eu tive oportunidade de conhecer mais sobre o SUS, que era algo que eu não sabia, até porque sempre tive plano de saúde e não dependia do SUS para nada. Tive oportunidade de conhecer um trabalho dentro da clínica da família e clínica da saúde eu estou tendo a oportunidade de ver a intervenção do profissional de educação física fazendo este trabalho integrado. (Estudantes 10, feminino, 24 anos).

Uma possível forma de atuação do profissional de Educação Física na ABS é a realização da prática corporal em saúde, que é um instrumento utilizado como prática de cuidado. Segundo alguns autores ${ }^{49,50}$, esta prática caminha para uma ampliação no convívio em relação ao usuário do serviço de saúde, pois passa 
a ter uma maior aproximação entre os saberes populares e acadêmicos, favorecendo a superação do modelo biomédico e prescritivo segundo o qual as atividades físicas/exercícios físicos têm sido normalmente desenvolvidos.

\section{Trabalho em equipes multidisciplinares}

Os estudantes apresentam como pontos positivos, no trabalho desenvolvido em equipes multidisciplinares, a troca e ganho de experiências, pois tiveram a oportunidade de trabalhar em grupo e em diferentes situações:

O ponto positivo é que a pessoa é atendida na sua totalidade, ela é atendida em todas as suas necessidades em maioria física, mental, entre outras. (Estudante 25, feminino, 21 anos)

Não vejo ponto negativo relacionado à unidade básica de saúde e a estratégia de saúde da família, porque você tem que ter esse vínculo com a equipe multiprofissional para eles ajudarem, como o profissional de educaçáo física é único na comunidade, essa equipe ajuda nessa criação de vínculo com a comunidade. (Estudante 8, feminino, 28 anos).

Freitas $^{51}$ apresenta alguns relatos sobre este tipo de trabalho multidisciplinar porque, segundo a autora, há uma facilitação na abordagem junto ao usuário em que este deixa de ter $\mathrm{o}$ atendimento somente pela consulta com médico, enfermeiro ou técnico de enfermagem, ampliando as possibilidades de acolher este usuário de forma interdisciplinar.

FonsÊCA et al. ${ }^{11}$ reforçam que este tipo de trabalho na atenção primária à saúde é importante, pois os estudantes que participaram do PET-Saúde, relataram ter presenciado essa aproximaçáo de forma muito produtiva, em que há uma interação entre os profissionais do serviço e os alunos em prol de um melhor cuidado da comunidade.

Embora muitos estudantes relatem pontos positivos na participação em equipes multidisciplinares, a maioria não sabia e/ou não tinha tido a oportunidade de viver esse momento antes de entrar no PEU, pois até então suas experiências em relação à Educação Física se restringiam às academias de ginástica, aos trabalhos personalizados ou outros com poucas informações sobre atuação na atenção básica.

\section{Aplicaçáo dos conhecimentos adquiridos}

Ao serem indagados sobre a eventual aplicação dos conhecimentos vivenciados no projeto em suas vidas, os estudantes destacaram a importância desta experiência única de contato com as pessoas. Uma possível interpretaçáo pode estar associada ao contexto em que o PEU está inserido (no bairro de Ramos). Isto porque nesse local, os alunos relataram a forma acolhedora e o profícuo campo de aprendizagem, a partir das práticas corporais desenvolvidas como ação permanente no programa.

\begin{abstract}
Viver com estas senhoras este tempo me fez pensar nesta idade (na terceira idade), porque não tinha pensado antes ter um carinho especial por elas, coisa que eu não tinha tido ainda. E como eu não sou rica, mas sou de uma realidade destas pessoas, isso me faz entender melhor esses determinantes e porque essas pessoas sofrem tanto, porque essas pessoas precisam de profissionais que trabalhem para elas, porque às vezes a gente fica naquele mundinho de gente bonita e sarada e, até eu mesmo, na escola na aula de educação física acostumada com criança e aqui fora, dizer assim, numa comunidade elas carecem muito deste tipo de serviço, coisa que não imaginava que era tanto [...]. (Estudante 10, feminino, 24 anos).
\end{abstract}

A vivência no estágio foi muito boa e percebi que o acolhimento é a forma que mais satisfaz o trabalho de todos lá e abriu a porta para mim de que há uma possibilidade de trabalho para o professor de educaçáo física na saúde da família. (Estudante 7, masculino, 22 anos).

Martinez, Carneiro, Campos et al. ${ }^{52}$ implementaram um curso de Educaçáo Física com referencial teórico e metodológico da Saúde Pública. Reafirmam a questão do diálogo, pois notaram que há uma aproximação entre teoria e prática na relação entre os estudantes e os participantes das práticas corporais.

Esse tipo de interaçấo contribui para as transformaçôes na prática em saúde dentro do contexto da atenção primária, porque há um protagonismo do estudante e amplia a potencialidade das articulaçóes entre ensino/ serviço/comunidade por meio do trabalho inter/ multidisciplinar, bem como auxilia na reorganização da formação destes alunos ${ }^{44}$.

A partir do exposto, foi possível observar que as percepçôes dos estudantes de Educação Física em atuação na Estratégia Saúde da Família apontaram 
para significados associados ao exercício físico ainda em uma perspectiva prescritiva e medicamentosa, embora em alguns momentos anunciem uma possibilidade de ampliação desse olhar. Isso fica evidenciado quando se verifica as associaçôes feitas em relação ao cuidado, pois as enunciaçóes têm similitude ao que é proposto pelas práticas corporais/atividades físicas no campo da saúde. No que tange à representação de saúde pública, muitas vezes encontrou-se uma perspectiva negativa, que pode estar atrelada ao pouco contato com o sistema público de saúde durante a graduação e/ou às suas experiências (pessoais ou familiares) negativas com o sistema de saúde. Os estudantes percebem sua participação de forma favorável neste setor, além de visualizarem modificaçôes significativas em sua formação, a partir da intervenção multidisciplinar.

As representaçóes sociais dos estudantes de suas experiências na participação do PEU podem ser interessantes para estimular que outras iniciativas sejam desenvolvidas para favorecer a articulação ensino/extensão/pesquisa/comunidade. Visto que essas experiências prolongadas também podem alavancar um interesse vinculado a luta pelo SUS.

\section{Notas}

a. Foram realizadas duas combinações (Representação + Saúde (79 artigos recuperados); Representações + Saúde (131)). Desse total 14 foram incluídas para análise, pois tratavam diretamente sobre representação de saúde em seus objetos, entretanto, três foram ensaios, e duas, mesmo apontando sobre representaçóes de saúde, acabaram por abordar representações de idoso saudável e alimentação saudável, fugindo do foco que se pretendeu nessa rápida busca. É importante ressaltar que as exclusóes realizadas dos 196 artigos que não entraram para análise se deram porque eles tratavam privilegiadamente da doença.

b. Entende-se que a interprofissionalidade está vinculada ao trabalho em equipe, que reflete em conjunto para buscar possibilidades de resolução das situaçóes prementes. As condutas devem ser pactuadas, geradas a partir dos debates que suscitam em uma construçáo coletiva considerando as particularidades em seus diferentes núcleos de saberes ${ }^{12}$.

c. SANTOS ${ }^{17}$ menciona que a crise do paradigma dominante é o resultado interativo de uma pluralidade de condiçóes. [...] A primeira observação, que não é tão trivial quanto parece, é que a identificação dos limites, das insuficiências estruturais do paradigma científico moderno é o resultado do grande avanço no conhecimento que ele propiciou. $\mathrm{O}$ aprofundamento do conhecimento permitiu ver a fragilidade dos pilares em que se funda. [...] (p. 54). Na fase de transição e de revolução científica, esta insegurança resulta ainda do fato de a nossa reflexão epistemológica ser muito mais avançada e sofisticada que a nossa prática científica (p. 71).

d. Pensando no entrelaçamento dessas abordagens tornou-se necessária a análise da grade curricular do curso, para que fosse possível compreender as contribuiçóes do ensino no desenvolvimento do pensamento crítico para a realidade encontrada nessa relação ensino/serviço/pesquisa/comunidade.

e. De acordo com as Diretrizes do Núcleo de Apoio à Saúde da Família" "Conhecer o território na perspectiva de suas nuances sociopolíticas e dos equipamentos que possam ser potencialmente trabalhados para o fomento das práticas corporais/atividade física” (p. 147).

f. "Os Conselhos Distritais de Saúde são compostos por vinte e cinco por cento de representantes de prestadores de serviços de saúde, público e privado e vinte e cinco por cento de representantes de profissionais de saúde em unidades do SUS e que atuem na área, e de cinquenta por cento de representantes de entidades de usuários do sistema de saúde do Distrito". Disponível em: http://conselhodistrital32.blogspot.com/p/o-que-e-conselho-distrital-de-saude.html Acesso em: 10 abr. 2018.

g. A consulta compartilhada é "a intenção é possibilitar a troca de saberes e de práticas em ato, gerando experiência para ambos os profissionais envolvidos”, com vistas para uma clínica ampliada ${ }^{19}$.

h. Disponível em: http://www.rio.rj.gov.br/dlstatic/10112/3700816/4128745/PMS_20142017.pdf Acesso em: 20 nov. 2016. 


\title{
Agradecimentos
}

Agradecemos à unidade de saúde pela parceria e a todos os estudantes que participaram do projeto.

\section{Conflito de interesses}

Não houve fonte de financiamento, tão pouco há conflito de interesse.

\begin{abstract}
Family Health Representation by students participating in a university extension project

This study develops through the articulation between teaching/service/research/community, once that it originates from a university outreach project (PEU) within the scope of the Family Health Strategy, whose objective was to analyze the representations of Physical Education students in the Family Health Strategy at a Municipal Health Center in Rio de Janeiro. It is quali and quanti research, in which the quantitative was approached through the Central Nucleus of Social Representations (SR) through the free associations of ideas and the qualitative, through the theoretical-methodological reference through the procedural approach. It was possible to show that students perceive their participation in this sector favorably, they also visualize significant modifications in their formation through the multidisciplinary intervention.
\end{abstract}

KeYwords: Physical Education; Exercise; Higher Education; Primary Health Care; Unified Health System.

\section{Referências}

1. Santos B. A universidade no século XXI: para uma reforma democrática e emancipatória da Universidade. $3^{a}$ Edição. São Paulo: Cortez; 2011.

2. Freire P. Pedagogia da autonomia: saberes necessários à prática educativa. 22a Edição. São Paulo: Paz e Terra; 1996.

3. Shimizu HE, Silva JR, Moura LM, Bermúdez XPD, Odeh MM. A estrutura das representaçóes sociais sobre saúde e doença entre membros de movimentos sociais. [citado 14 abr 2018]. Ciênc Saúde Coletiva. 2015;20:2899-2910. Disponível em: http:/www.scielo.br/scielo.php?script=sci_arttext\&pid=S1413-81232015000902899\&lng=en.

4. Garelli F, Mengascini A, Cordero S, Dumrauf, A. Formación docente y representaciones sobre Salud: caminos para la Educación en Salud desde una mirada crítica. [citado 14 abr 2018]. Ensaio Pesq Educ Ciênc. 2017,19:1-20. Disponível em: https://dx.doi.org/10.1590/1983-21172017190106.

5. Tura LFR, Bursztyn I, Carvalho DM, Arruda A, Silva AO. Representaçóes Sociais de saúde construídas por idosos do oeste paraense. [citado 16 abr 2018]. Rev Bras Geriatr Gerontol. 2011;14:743-752. Disponível em: http://www. scielo.br/scielo.php?script=sci_arttext\&pid=S1809-98232011000400013\&lng=pt.

6. Silva SPC, Menandro MCS. As representaçóes sociais da saúde e de seus cuidados para homens e mulheres idosos. [citado 16 abr 2018]. Saúde Soc. 2014;23:626-640. Disponível em: http://www.scielo.br/scielo.php?script=sci_ arttext\&pid=S0104-12902014000200626\&lng=pt.

7. Lopes MJM, Bueno ALM. Saúde Pública é...: permanências e modernidades nas representaçóes de universitários. [citado 18 abr 2018]. Saúde Soc. 2007;16:92-101. Disponível em: http://www.scielo.br/scielo.php?script=sci_ arttext\&pid=S0104-12902007000300009\&lng=pt.

8. Oliveira DC, Sá CP. Representações sociais da saúde e doença e implicaçôes para o cuidar em enfermagem: uma análise estrutural. [citado 16 abr 2018]. Rev Bras Enferm. 2001;54:608-622. Disponível em: http://www.scielo.br/scielo. php?script=sci_arttext\&pid=S0034-71672001000400009\&lng=pt.

9. Câmara AMCS, Melo VLC, Gomes MGP et al. Percepção do processo saúde-doença: significados e valores da educação 
em saúde. [citado 18 abr 2018]. Rev Bras Educ Médica, 2012;36:40-50. Disponível em: https://dx.doi.org/10.1590/ S0100-55022012000200006.

10. Cromack LMF, Bursztyn I, Tura LFR. O olhar do adolescente sobre saúde: um estudo de representaçôes sociais. [citado 18 abr 2018]. Ciênc. Saúde Coletiva. 2009;14:627-634. Disponível em: http://www.scielo.br/scielo.php?script=sci_ arttext\&pid=S1413-81232009000200031\&lng=pt.

11. Fonseca GS, Junqueira SR, Zilbovicius C, Araújo ME. Educação pelo trabalho: reorientando a formação de profissionais da saúde. [citado 19 abr 2018]. Interface. 2014;18(50):571-583. Disponível em: http://www.scielo.br/scielo. php?script=sci_arttext\&pid=S1414-32832014000300571\&lng=en \&nrm=iso\&tlng=pt.

12. Batista NA. Educação interprofissional em saúde: concepçóes e práticas. Cad FNEPAS. 2012;2:25-28. Disponível em: http://www.fnepas.org.br/artigos_caderno/v2/educacao_interprofissional.pdf.

13. Pedrosa OP, Leal AF. A inserção do profissional de educação física na estratégia saúde da família em uma capital do norte do Brasil. [citado 20 abr 2018]. Movimento. 2012;18;2:235-253. Disponível em: https://seer.ufrgs.br/Movimento/ article/view/26461.

14. Pasquim HM. Saúde coletiva nos cursos de graduação em Educação Física. [citado 20 abr 2018]. Saúde Soc. 2010;19;1:193200. Disponível em: http://www.scielo.br/scielo.php?script=sci_arttext\&pid=S0104-12902010000100016\&lng=en\& nrm=iso\&tlng=pt.

15. Falci D, Belisário S. A inserção do profissional de educação física na atenção primária à saúde e os desafios em sua formação. [citado 20 abr 2018]. Interface. 2013;17(47):885-899. Disponível em: http://www.scielo.br/scielo. php?script=sci_arttext $\&$ pid $=S 1414-32832013000400010 \& \operatorname{lng}=$ en $\&$ nrm $=$ iso $\&$ tlng=pt.

16. Domingos Sobrinho M. Habitus e representaçôes sociais: questôes para o estudo de identidades coletivas. In: Moreira ASP \& Oliveira DC, organizadores. Estudos interdisciplinares de representação social. Goiânia: Editora AB; 1998. p. 117-130.

17. Santos BS. Um discurso sobre as ciências na transição para uma ciência pós-moderna. [citado 19 abr 2018]. Estudos Avançados. 1988;2(2):46-71. Disponível em: http://www.scielo.br/scielo.php?script=sci_arttext\&pid =S0103-40141988000200007.

18. Brasil. Ministério da Saúde. Secretaria de Atenção à Saúde. Departamento de Atenção Básica. Diretrizes do NASF. Brasília: Ministério da Saúde, 2009.

19. Brasil. Ministério da Saúde, Secretaria de Atenção à saúde. Clínica ampliada e compartilhada. Ministério da Saúde, Secretaria de Atenção à Saúde, Política Nacional de Humanização da Atenção e Gestão do SUS. Brasília: Ministério da Saúde, 2009.

20. Minayo MCS, Deslandes SF, Gomes R. Pesquisa social: teoria, método e criatividade. Rio de Janeiro: Vozes; 2012.

21. Sá CP. Núcleo central das representações sociais. 2a Edição. Petrópolis: Vozes; 2002.

22. Espírito-Santo G. Determinantes sociais de saúde, exercício físico e lazer de adultos jovens moradores da Comunidade da Matriz. [Tese de doutorado]. Rio de Janeiro (RJ): Universidade Gama Filho; 2010.

23. Jodelet D. Loucuras e representações sociais. 2a Edição. Petrópolis: Vozes; 2005.

24. Arruda A. Despertando do pesadelo: a interpretação. In Moreira ASP. Perspectivas teórico-metodológicas em representaçôes sociais. 1 ${ }^{\text {a }}$ Edição. Joâo Pessoa: Editora Universitária UFPB; 2005; p. 229-258.

25. Bardin L. Análise do discurso. 70a Edição. São Paulo: Ediçóes; 2011.

26. Brasil. Ministério da Saúde. Conselho Nacional de Saúde. [internet], 2012 [citado 04 out 2015]. Disponível em: http://conselho.saude.gov.br/web_comissoes/conep/.

27. Rocha JV, Rocha SV, Rodrigues WKM, Valença Neto PF, Vasconcelos LRC. Effectiveness of a physical activity program on indicators of health status of users of the Family Health Strategy. Fisioter. [citado 11 jun 2017]. Movimento. 2015;28(2):365-372. Disponível em: http://www.scielo.br/scielo.php?script=sci_arttext\&pid=S0103$51502015000200365 \& \operatorname{lng}=$ pt\&nrm=iso.

28. Pozena R; Cunha NFS. Projeto "construindo um futuro saudável através da prática da atividade física diária". [citado 11 jun 2017]. Saúde Soc. 2009;18(supl 1):52-56. Disponível em: http://www.scielo.br/scielo.php?script=sci_ arttext\&pid=S0104-12902009000500009\&lng=pt\&nrm=iso.

29. Palma A; Vilaça MM. O sedentarismo da epidemiologia. [citado 05 abr 2018]. Rev Bras Ciênc Esporte. 2010;31:105119. Disponível em: http://www.rbce.cbce.org.br/index.php/RBCE/article/viewFile/506/415.

30. Ferreira MS, Castiel LD, Cardoso MHCA. Atividade física na perspectiva da Nova Promoção da Saúde: contradiçôes de um programa institucional. [citado 05 abr 2018]. Ciênc Saúde Col. 2011;1:865-872. Disponível em: http://www. scielo.br/scielo.php?script=sci_arttext\&pid=S1413-81232011000700018\&lng=en\&nrm=iso\&tlng=pt. 
31. Nogueira JAD; Bosi MLM. Saúde Coletiva e Educação Física: distanciamentos e interfaces. [citado 20 ago 2017]. Ciênc Saúde Col. 2017;6:1913-1922. Disponível em: http://www.scielo.br/scielo.php?script=sci_arttext\&pid=S1413$-81232017002601913 \& \operatorname{lng}=$ en\&nrm=iso.

32. Minayo MCS, Hartz ZMA, Buss PM. Qualidade de vida e saúde: um debate necessário. [citado 02 ago 2018]. Ciênc Saúde Col. 2000;5;1:7-18. Disponível em: http://www.scielo.br/scielo.php?script=sci_arttext\&pid=S1413$-81232000000100002 \& \operatorname{lng}=$ en $\&$ nrm $=$ iso\&tlng=pt.

33. Silva AC, Lüdorf SMA. Possíveis relações entre corpo saúde e envelhecimento do professor de Educação Física. [citado 06 ago 2018]. Movimento. 2012;2:187-205. Disponível em: https://seer.ufrgs.br/Movimento/article/view/18807.

34. Rodrigues JD, Ferreira D, Silva P, Caminha I, Farias Junior JC. Inserção e atuação do profissional de educação física na atenção básica à saúde: revisão sistemática. [citado 22 ago 2018]. Rev Bras Ativ Fís Saúde. 2013;18;1:5-15. Disponível em: http://rbafs.org.br/RBAFS/article/view/2390.

35. Guarda FRB, Silva RN, Araujo Junior JLAC, Freitas MIF, Santos Neto PM. Intervenção do profissional de educação física: formação, perfil e competências para atuar no Programa Academia da Saúde. [citado 22 ago 2018]. Rev Pan-Amaz Saúde. 2014;5; 4:63-75. Disponível em: http://scielo.iec.gov.br/scielo.php?script=sci_arttext\&pid $=$ S2176-62232014000400008.

36. Bilibio LFS. Esquecimento ativo e práticas corporais na saúde. In: Fraga AB; Carvalho YM; Gomes IM, organizadores. As práticas corporais no campo da saúde. São Paulo: Hucitec, 2013, p. 117-138.

37. Rodrigues MP, Lima KC, Roncalli AG. A representação social do cuidado no programa saúde da família na cidade de Natal. [citado 18 abr 2018]. Ciênc Saúde Col. 2008;13:71-82. Disponível em: http://www.scielo.br/scielo. php?script=sci_arttext\&pid=S1413-81232008000100012\&lng=pt.

38. Santos FPA, Acioli S, Rodrigues VP, Machado JC, Souza MS, Couto TA. Práticas de cuidado da enfermeira na Estratégia Saúde da Família. [citado 25 ago 2018]. Rev Bras Enferm, 2016;69(6):124-1131. Disponível em: http://www.scielo. br/scielo.php?pid=S0034-71672016000601124\&script=sci_abstract\&tlng=pt.

39. Freitas FF, Brasil FK, Silva CL. Práticas corporais e saúde novos olhares. Rev Bras Ciênc Esporte. 2006;27(3):169-183.

40. Gutierrez DMD, Minayo MCS. Produção de conhecimento sobre cuidados da saúde no âmbito da família. [citado 19 abr 2018]. Ciênc Saúde Coletiva. 2010;15:1497-1508. Disponível em: http://www.scielo.br/scielo.php?script=sci_ arttext\&pid=S1413-81232010000700062\&lng=pt.

41. Maximino VS, Liberman F, Frutuoso MF, Mendes R. Profissionais como produtores de redes: tramas e conexôes no cuidado em saúde. [citado 19 abr 2018]. Saúde Soc. 2017;26:435-447. Disponível em: <http://www.scielo.br/scielo. php?script=sci_arttext $\&$ pid $=$ S0104-12902017000200435\&lng=pt $>$.

42. Cavalcante JK, Soares FJP, Correa DS. Desenvolvimento discente no estágio em Estratégia Saúde da Família. [citado 25 ago 2018]. Rev Bras Educ Med. 2014;38;1:15-24. Disponível em: http://www.scielo.br/scielo.php?script=sci_ arttext\&pid=S0100-55022014000100003\&lng=en\&nrm=iso\&tlng=pt.

43. Leite A, Cirino DCS, Gomes GB et al. A vivencia de estudantes do curso técnico em enfermagem na extensão popular. In Vasconcelos EM, Cruz JSC, organizadores. Educação popular na formação universitária: reflexôes com base em uma experiência. São Paulo: Hucitec; 2011. p. 140-144.

44. Silva AFL, Ribeiro CDM, Silva Júnior AG. Pensando extensão universitária como campo de formação em saúde: uma experiência na Universidade Federal Fluminense, Brasil. [citado 18 abr 2018]. Interface; 2013;17:371-384. Disponível em: http://www.scielo.br/scielo.php?script=sci_arttext\&pid=S1414-32832013000200010\&lng=pt.

45. Freire P. Pedagogia da esperança: um reencontro com a pedagogia do oprimido. Rio de Janeiro: Paz e Terra; 1992.

46. Caldas JB, Lopes ACS, Mendonça RD, et al. A percepção de alunos quanto ao Programa de Educação Pelo Trabalho para a Saúde - PET-Saúde. [citado 24 ago 2018]. Rev Bras Educ Med. 2012:33-41. Disponível em: http://www.scielo. $\mathrm{br} /$ scielo.php?script=sci_arttext\&pid=S0100-55022012000300006.

47. Santos BS. Pela mão de Alice: o social e o político na pós-modernidade. 14a edição. São Paulo: Cortez; 2013.

48. Santos SFS, Benedetti TRB. Cenário de implantação do Núcleo de Apoio a Saúde da Família e a inserção do profissional de Educação Física. [citado 22 ago 2018]. Rev Bras Ativ Fís Saúde. 2012;17(3):188-194. Disponível em: http://rbafs. org.br/RBAFS/article/view/1857.

49. Fraga AB, Carvalho YM, Gomes IM. As práticas corporais no campo da Saúde. São Paulo: Hucitec; 2013.

50. Pinheiro R, Ceccim BC, Mattos A. Ensinar saúde: a integralidade e o SUS nos cursos de graduaçáo na área da saúde. Rio de Janeiro: CEPESC: IMS/UERJ: ABRASCO, 2a edição, editor. Rio de Janeiro: 336; 2011.

51. Freitas F. A Educação Física no serviço público de saúde. São Paulo: Hucitec; 2007.

52. Matinez JFN, Carneiro JA, Campos MH, et al. Práticas corporais e SUS: tensóes teóricas e práticas. In: Fraga AB, 
Carvalho YM, Gomes IM. As práticas corporais no campo da saúde. São Paulo: Hucitec; 2013: 139-177.

\begin{tabular}{r|l} 
ENDEREÇO & \\
Diogo Gonçalves de Souza de Oliveira & Submetido: 20/06/2018 \\
Uniabeu Centro Universitário & 1a. Revisão: 15/10/2018 \\
Rua Itaiara, 301- Centro & 2a. revisão: 03/03/2019 \\
26113-400 - Belford Roxo - RJ - Brasil & Aceito: 21/04/2019 \\
E-mails: prof.diogo.oliveira@hotmail.com & \\
diogo.gsoliveira@gmail.com & \\
\end{tabular}

Rev Bras Educ Fís Esporte, (São Paulo) 2021J an-Mar;35(1):143-157 • 157 